\title{
Aulas virtuais: uma discussão sobre a interação no aprendizado de língua estrangeira em tempos de pandemia
}

\author{
Cours virtuel: une discussion à propos de l'interaction dans l'apprentissage d'une langue étrangère en temps \\ de pandémie
}

\section{Nina Rioult}

Universidade Federal do Fluminense - UFF - Rio de Janeiro - Brasil

\section{Adilson Marron}

Universidade Federal do Fluminense - UFF - Rio de Janeiro - Brasil

\section{Telma Pereira}

Universidade Federal do Fluminense - UFF - Rio de Janeiro - Brasil

\begin{abstract}
Resumo: Este artigo fornece um retorno sobre a rápida transição dos cursos presenciais para a modalidade remota no contexto da pandemia Covid-19, que afetou o mundo inteiro desde março de 2020. Revelando nossa experiência como jovens professores de francês, inseridos em projetos de extensão na Universidade Federal Fluminense (UFF), abordaremos os desafios de implantação de atividades interativas no contexto de cursos ministrados por videoconferência. De fato, essa transição levantou muitas questões sobre como gerenciar as interações na sala de aula virtual, sobretudo o que diz respeito às interações aluno-aluno. Após apresentar os principais marcos que constituem a história da educação online no Brasil, discutiremos os trabalhos teóricos que nos permitem analisar as especificidades das interações online. Em seguida, apresentaremos como essa transição se desenrolou em um curso de extensão de línguas na UFF, antes de apresentar com mais detalhes exemplos de atividades que possibilitaram adaptar as aulas presenciais e estimular as interações entre alunos de níveis iniciantes e avançados. A partir dessa experiência, concluímos que, para promover esse tipo de interação, é importante tanto oferecer um quadro educacional mais flexível do que na modalidade presencial, quanto garantir que o professor não esteja mais no centro do processo interativo, chegando às vezes a desaparecer gradualmente.
\end{abstract}

Palavras-chave: Educação online; Pandemia de COVID-19; Interações entre alunos.

Abstract: Le présent article offre un retour d'expérience sur la transition précipitée des cours présentiels vers des cours en ligne dans le contexte de la pandémie de Covid-19, qui affecte le monde entier depuis mars 2020. En retraçant notre expérience de professeurs de langue française intervenant à l'Université Fédérale Fluminense (UFF), nous nous concentrerons sur les défis liés à la mise en place d'activités interactives dans le cadre de cours donnés par visioconférence. De fait, cette transition a suscité de nombreuses interrogations sur la manière de gérer les interactions dans la salle de classe virtuelle, en particulier en ce qui concerne les interactions apprenant-apprenant. Après avoir présenté les principaux jalons qui constituent l'histoire de l'enseignement en ligne au Brésil, nous aborderons les différents travaux théoriques permettant d'analyser les spécificités des interactions en ligne. Nous présenterons ensuite la manière dont cette transition s'est déroulée à l'UFF, avant d'exposer plus spécifiquement quelques activités ayant permis d'adapter les cours et d'encourager les interactions entre apprenants aux niveaux débutant et avancé. À partir de cette expérience, nous concluons que, afin de favoriser ce type d'interactions, il est important à la fois de proposer un cadre éducatif plus souple qu'en présentiel, et de faire en sorte que le professeur ne soit plus au centre des interactions, voire, parfois, qu'il s'efface progressivement.

Mots-clés: enseignement en ligne ; pandémie Covid-19 ; interactions entre apprenants 


\section{Introdução}

A pandemia de Covid-19 de 2020 afetou as nossas vidas de várias maneiras, tanto no aspecto pessoal quanto profissional. Para nós, professores de língua estrangeira, a chegada do vírus no território brasileiro, e a decorrente quarentena que foi adotada, nos levaram a transformar radicalmente a nossa prática profissional. Com esse artigo, apresentamos um relato baseado em nossa experiência como professores de francês de um projeto de extensão da Universidade Federal Fluminense (UFF). Em menos de uma semana, esse projeto realizou uma transição para as aulas online, o que levantou vários questionamentos em relação à transposição didática das aulas presenciais.

Em seu artigo intitulado Ensino a distância: horizontes para o ensino de línguas estrangeiras, o professor Celso Tumolo afirma que através do ensino online as dificuldades sociais são atenuadas, uma vez que os custos do ensino remoto são mais acessíveis que o ensino presencial, e que a assiduidade dos alunos por conta das demandas de trabalho induz a uma redução da exclusão social (TUMOLO, 2006). Porém, no contexto brasileiro, a vantagem da acessibilidade a essa modalidade de ensino constitui ao mesmo tempo a sua maior desvantagem. De fato, NASCIMENTO E SANTOS (2020), ao mencionar dados da Agência Nacional de Telecomunicações (Anatel) divulgados em 2018, apontam que o acesso à internet ainda é muito desigual: "apenas $9 \%$ dos domicílios brasileiros das camadas de renda $D$ e $E$ possui computador, $55 \%$ dos acessos móveis do país são pré-pagos e 33\% das residências não possuem qualquer tipo de conexão com a internet". Desta forma, as autoras denunciam o fato de que a modalidade de ensino a distância é fator de agravação das desigualdades sociais e qualificam a generalização desse ensino efetuada durante a epidemia de Covid19 de "normalidade excludente e macabra".

Como veremos, no caso do projeto de extensão da UFF, as dificuldades de acesso às aulas remotas também fizeram parte dessa transição abrupta. Além disso, quando a transição para aulas online ocorreu vários questionamentos surgiram relativos à transposição didática das aulas de língua estrangeira: como adaptar as nossas aulas a esse novo contexto? Em nossa prática como professores percebemos que uma das maiores dificuldades foi incentivar e gerenciar as interações na sala de aula virtual.

De fato, o aprendizado de uma língua estrangeira envolve o desenvolvimento de várias habilidades, dentre as quais a interação oral é fundamental. Porém, a aquisição desta habilidade geralmente requer a possibilidade de dois interlocutores interagirem em um espaço-tempo comum. Nessa nova configuração, como fazer com que os alunos possam desenvolver uma competência oral quando as condições técnicas falham ou não são satisfatórias? Que estratégias adotar para minimizar a inevitável perda de qualidade das interações?

Nesse artigo, apresentaremos primeiro uma parte teórica sobre o histórico do ensino online no Brasil e a especificidade das interações nas aulas online. Em uma segunda parte, mostraremos como os quadros geralmente descritos nas pesquisas diferem daqueles que experimentamos durante a quarentena. De fato, muitas das recomendações feitas pela literatura sobre o ensino online não se aplicam ao contexto pandêmico que conhecemos, pela ausência de boas condições técnicas. Por fim, apresentaremos alguns exemplos de atividades que foram desenvolvidas nesse contexto totalmente inédito.

\section{Quadro teórico \\ 1.1 O ensino online no Brasil}

O uso da tecnologia tem crescido de forma significativa para professores, alunos e pesquisadores. O computador tem sido utilizado como instrumento de trabalho cada vez mais frequente, e em alguns casos, certamente indispensável. Mas o ensino de línguas através do computador no país é recente, sobretudo porque o ensino de línguas de forma remota no mundo inteiro também é relativamente recente. Lamy e Hampel (2007) afirmam que a aprendizagem mediada pelo computador teria se iniciado nos anos 90 , quando instituições começaram a criar redes de envio de textos de forma assíncrona. Desde então, foram implantadas ferramentas comunicativas de forma gradual para que a aprendizagem de forma síncrona 
pudesse ser estabelecida através de videoconferências.

O ensino de línguas mediado pelo computador passou então a ser chamado de CALL (Computer Assisted Language Learning), sendo posteriormente considerado um movimento que pode ser dividido e analisado em três fases: CALL behaviorista, CALL comunicativa e CALL integrativa. De forma resumida, na primeira fase, a CALL behaviorista, utilizava-se uma abordagem baseada na linguística estruturalista, com a criação de programas que se baseavam na repetição de exercícios constantes. Essa fase durou até o final da década de 70, dando lugar a uma abordagem mais comunicativa, visando o desenvolvimento mental interno, entendido como formas diferentes de organização mental que possibilitam as diferentes maneiras do indivíduo relacionar-se com a realidade que o rodeia através do processo de interação, era o início da CALL comunicativa. Através dessa perspectiva, praticar a língua alvo de forma mais indutiva, a interação aluno-aluno ganhou importância frente à interação professor-aluno. Por fim, a CALL integrativa, considerada contemporânea, é baseada em uma perspectiva sócio cognitivista de aprendizagem, o que propõe ao aluno uma atuação mais discursiva, participante da comunidade na qual está inserido, afinal não é mais satisfatório oferecer apenas as estruturas linguísticas para prática e compreensão (KERN, WARSCHAUER, 2000).

Para o caso brasileiro, as fases da CALL não seriam consideradas adequadas, uma vez que no Brasil, a chegada dos computadores foi bastante tardia, sobretudo nas escolas (PAIVA, 2019). Com a chegada dos mainframes, as escolas brasileiras começaram timidamente a autenticar os cartões dos alunos, a utilizar os recursos para digitação de provas e textos para as salas de aula, oferecendo dessa forma uma economia de tempo sem precedentes para os professores. Contudo, o início do ensino a distância no Brasil poderia ser inserido na fase comunicativa com a criação do projeto Telecurso $2^{\circ}$ grau em 1977, uma parceria da Fundação Padre Anchieta, mantenedora da TV Cultura, e a Fundação Roberto Marinho (TV Globo). Posteriormente, a partir de 1991, a TV Escola colocou no ar o projeto Salto para o futuro, um programa interativo que se tornou referência para professores e educadores de todo o país. O programa conta com orientadores educacionais, que coordenam os trabalhos em aproximadamente 600 pontos virtuais, distribuídos em todo o território brasileiro e tem momentos interativos que possibilitam aos professores, reunidos nesses espaços, um contato síncrono com os debatedores dos temas em análise.

Nos anos 90, a criação da BITNET (Because It is Time Network), a primeira rede de comunicação individual entre os professores universitários representou um avanço tecnológico e um ganho para a comunidade científica. A professora Heloísa Collins da PUC-SP foi a pioneira no ensino de línguas mediado pelo computador através da utilização do Bulletin Board System, um servidor equipado com um aplicativo para interação de mensagens entre os usuários, armazenamento ou troca de arquivos, além da possibilidade de jogos entre um ou mais usuários conectados ao modem através das redes telefônicas.

A inauguração do primeiro laboratório de computadores para alunos da faculdade de letras da UFMG, com apoio do projeto PROIN da CAPES, no final de 1997, permitiu que a universidade brasileira fosse pioneira na oferta de disciplinas online, tanto na graduação, como na pós-graduação (PAIVA, 2019). Ainda, a partir de 2005, o MEC e a Secretaria de Educação a Distância criaram o sistema Universidade Aberta do Brasil (UAB), um programa articulador entre governo federal e entes federativos que apoia instituições públicas de ensino superior (IPES) a oferecerem cursos de nível superior e de pósgraduação por meio do uso da modalidade de ensino virtual, com a finalidade de expandir e interiorizar a oferta de cursos e programas de educação superior no país, sendo gerenciado pela CAPES.

Certamente, são divergentes as opiniões sobre o ensino a distância, sobretudo em tempos de pandemia. Ainda que para Hargreaves (2010), a falta de comunicação face-a-face entre alunos e o professor seja o maior tipo de problema neste tipo de interação, inúmeros são os benefícios que essa modalidade de ensino oferece segundo Keremidchieva (2001), de 
forma que a comunicação entre alunos e professores no ensino remoto é mais intensa e eficiente, afinal são frequentes as atividades e o fluxo de exercícios, logo um canal ativo de mensagens é aberto, plataformas virtuais são utilizadas para compartilhamento de informações e cada vez mais os alunos ganham um papel autônomo na aprendizagem. A formação atualizada e diversificada, possível na modalidade a distância, seria a melhor forma de evitar a desqualificação da força de trabalho e a exclusão social, provocando assim uma estabilidade social (BELLONI, 1999). De fato, é necessário ter grande autonomia nos estudos na modalidade a distância, sendo uma forma de ensino que possibilita a autoaprendizagem, com a mediação de recursos didáticos sistematicamente organizados, apresentados em diferentes suportes de informação, utilizados isoladamente ou combinados, e veiculados pelos diversos meios de comunicação (BRASIL, 1996). O ensino remoto também poderia contribuir para 0 ganho em escala na produção de material virtual, a possibilidade de aprimoramento deste material por uma equipe multidisciplinar de especialistas, assim como a possibilidade de interatividade e feedback imediatos através de videoconferências, assim como uma personalização do ensino para atender diferentes perfis de acordo com diferentes estratégias pedagógicas (STEIL, 2004).

Contudo, é importante afirmar que com o ensino a distância, algumas desvantagens podem ser observadas, sobretudo quando o sistema foi configurado e imposto pela pandemia. Segundo os resultados do censo 2018/2019 EAD.br realizado pela ABED (Associação Brasileira de Ensino a Distância), anterior a situação de pandemia, a evasão dos alunos era o principal obstáculo para essa modalidade de ensino. Em segundo lugar como fator mais desafiador, está a resistência dos educadores à modalidade. Em terceiro aparecem as dificuldades de adaptação da educação presencial para ensino remoto e, em quarto, a resistência dos alunos ao novo formato. As causas de evasão mais apontadas pelas instituições foram falta de tempo do aluno para estudar e participar do curso, acúmulo de atividades no trabalho e a dificuldades de se adaptar à metodologia.

Ainda assim, precisamos observar atentamente a sociedade brasileira para nos perguntarmos se todos esses recursos virtuais seriam de fato eficazes diante de problemas sociais e estruturais graves presentes há muitos anos em nosso país. O adiamento da aplicação das provas do ENEM 2020 é um fator revelador na análise estrutural de uma população com graves deficiências, isto é, um país no qual um a cada quatro habitantes não possuem acesso à internet, segundo a Pesquisa Nacional por Amostra de Domicílios Contínua - Tecnologia da Informação e Comunicação (Pnad Contínua TIC) de 2018. Dados da pesquisa revelam que os três principais motivos para a não utilização da internet foram: falta de interesse em acessar (34,7\%), o serviço de acesso à web era caro $(25,4 \%)$ e nenhum morador sabia usar a internet (24,3\%). Contudo, 7,5\% disseram que não havia disponibilidade de rede na área residencial e 4,7\% justificaram o alto custo para obter a conexão.

A pesquisa apresenta ainda que, enquanto nas áreas rurais $20,8 \%$ não possuem internet pela falta de serviços locais disponíveis, essa é a realidade para apenas $1 \%$ nas áreas urbanas. No Norte, por exemplo, a indisponibilidade de serviços chega a 13,8\% da população, contra 1,9\% no Sudeste. Nesse cenário de desigualdade, a Pnad revela também que o Brasil ainda tem 2,1 milhões de domicílios onde há somente sinal analógico de TV. No estado do Rio de Janeiro, mais precisamente na cidade de Niterói, onde nosso artigo ganha base empírica, temos hoje $62,72 \%$ das residências com conexão de Internet, o maior índice entre os municípios fluminenses. Para o prefeito deste município, o programa Niterói Digital visa democratizar o acesso e o uso das tecnologias de informação e comunicação pelo conjunto da população, especialmente em regiões e bairros populares da cidade. Essa é uma meta ambiciosa para promover uma ampla inclusão digital principalmente nos segmentos mais pobres da sociedade.

Como vimos, o estabelecimento de aulas remotas no contexto brasileiro levanta vários questionamentos ligados à própria possibilidade de dar 
aulas desse modo. Além desses problemas estruturais, que detalharemos adiante, a modalidade remota demanda um mínimo letramento digital por parte dos usuários, e apresenta questões específicas às aulas de língua estrangeira, em particular no que concerne às interações a ser desenvolvidas. $\mathrm{Na}$ próxima parte, apresentaremos alguns pontos a fim de descrever as particularidades das interações nas aulas de língua estrangeira de forma remota.

\subsection{A questão das interações online nas} aulas de LE online

A competência interativa é essencial na aquisição da linguagem. De acordo com Bakhtin (2006, p. 125), "a interação verbal constitui assim a realidade fundamental da linguagem", ou seja, falar é interagir. Partindo desse pressuposto, podemos afirmar que aprender uma língua é aprender a interagir nessa língua. De fato, essa habilidade linguística é detalhadamente descrita no Quadro Europeu Comum de Referência para Línguas (doravante QECRL). Trata-se de uma habilidade bastante complexa porque ela engloba estratégias de produção e de recepção, assim como estratégias cognitivas e de cooperação (QECRL, 2001). O Quadro europeu apresenta alguns exemplos de interações que acontecem em nosso cotidiano, tais como: "transações, conversa informal, discussão informal ou formal, debate, entrevista, negociação, planejamento conjunto e cooperação prática com vista a um fim específico" (p. 112-113). Para abordar essas interações, podem ser feitas dramatizações curtas sobre, por exemplo, temas como "comprar pão na padaria" ou "comprar uma passagem". Para os níveis avançados, é comum propor aos aprendizes a realização de debates, muitas vezes acerca de um tema preestabelecido e distribuindo aos alunos papéis de personagens que têm opiniões antagônicas.

Cicurel (2011) considera que as interações em sala de aula constituem um tipo específico de interação, uma subcategoria, que goza de características próprias. A autora estabelece algumas especificidades dessas interações: 1) ela têm um objetivo cognitivo porque sempre têm como objetivo o acréscimo do conhecimento, 2) o lugar de interação é determinado por um status, que pode ser negociado pelos outros participantes, 3) são interações planejadas, 4) são interações que levam às atividades didáticas, mais ou menos formalizadas, 5) elas ocorrem em um tempo limitado e requerem uma focalização alta de todos os participantes, 6) elas acontecem dentro de um regime discursivo específico, na medida em que a própria linguagem é sempre um objeto de atenção, com uma atividade metalinguística constante.

A nosso ver, essas características, tais como descritas por Cicurel (2011), valem também para as aulas online. Porém, nas interações online, outros fatores, determinados por um suporte tecnológico, entram em jogo.

\subsection{As características das interações em} aulas online: a multimodalidade

De acordo com Chapelle (2009, apud GUICHON e COHEN, 2016), a multimodalidade é uma característica das aulas por videoconferências. Guichon e Cohen (2016) indicam que essas interações se dão por vários "modos", sendo eles definidos com representação semiótica, que pode ser textual, visual ou oral. No caso das aulas de língua, o modo textual pode ser realizado pelas interações no chat ou no Whatsapp, mas também pelas informações escritas na "lousa", por exemplo, em um documento Word ou PowerPoint compartilhado na tela. O modo visual é desempenhado pela própria imagem transmitida pela câmera (rostos e expressões faciais, corpos e gestos, roupas, meio ambiente ao redor, etc.) e também pelos elementos visuais expostos através do compartilhamento de tela (imagens, vídeos, etc.). Por fim, o modo oral se dá por meio dos sons transmitidos pelo microfone (vozes, sons ao redor) e por meio dos documentos compartilhados (trilha sonora, vídeo). Através desses três modos, a comunicação pode ser feita por meio de imagens (por exemplo, acenar com a mão ou a cabeça), de sons (falar no microfone) ou pela escrita (escrever no chat), de forma quase simultânea. 
Os autores afirmam que a multimodalidade pode incentivar a aprendizagem já que ela permite repetir a mesma informação por vários modos, no entanto pode também virar uma sobrecarga cognitiva se não for utilizada de forma adequada. Por isso, Guichon e Cohen (2016) apontam para a necessidade de o aprendiz adquirir uma "competência multimodal". Três habilidades precisariam ser desenvolvidas para que interações em situação multimodal sejam eficientes:

- Habilidades semiopragmáticas: aprender a usar criticamente vários modos simultaneamente. A esse respeito, os autores indicam que "terão de se tornar capazes não só na mudança de códigos linguísticos, mas também na mudança de modos semióticos"

- Habilidades psicocognitivas: aprender a trabalhar com uma ferramenta desconhecida, o que envolve fortes demandas emocionais.

- Habilidades socioculturais: aprender a lidar com diferenças interculturais na comunicação em espaços de aprendizagens virtuais e multimodais.

Para desenvolver essas habilidades, os aprendizes devem se familiarizar com os diversos modos da videoconferência, o que, como veremos mais adiante, foi longe de ser o nosso caso durante 0 contexto de quarentena.

Os mesmos autores ainda sugerem que 0 professor desenvolva também novas competências pedagógicas, para que este seja sensibilizado a todas as possibilidades semióticas das aulas mediadas por videoconferência e, por conseguinte, ser capaz de conceber tarefas didáticas adequadas ao aprendizado de língua mediado pela tecnologia. O professor estará ciente da variedade dos modos disponíveis e da interação entre os vários modos, assim como da multiplicidade de foco induzida por estes modos, para poder adaptar melhor a aula.

1.4 A noção de distância nas aulas por videoconferência

Como ressalta Macedo-Rouet (2009): "O interesse da videoconferência é precisamente o de poder cobrir a distância entre professores e aprendizes, através do face a face de forma virtual". De fato, em tempos de distanciamento social exigido pela pandemia de Covid-19, a videoconferência se mostrou ser uma ferramenta indispensável à continuação de nossas atividades. Ela permitiu reduzir pelo menos um pouco a distância geográfica que nos foi imposta repentinamente. Porém, a transição para aulas mediadas por videoconferência não resolve completamente os desafios impostos pela pandemia. Com efeito, no ensino a distância, as distâncias não se limitam ao espaço físico, mas a uma multiplicidade de categorias. Macedo Rouet cita Jacquinot (1993) que identificou, por exemplo, seis dimensões da distância: espacial, temporal, tecnológicas, sociocultural, socioeconômica, pedagógica.

Macedo-Rouet (2009) aponta também a teoria de distância transacional, idealizada por Moore (1993), sendo a distância transacional definida como um "espaço psicológico comunicacional entre alunos e instrutores". Ela depende de três variáveis: a estrutura, o diálogo e a autonomia dos aprendizes. A estrutura da aula e o diálogo são ligados à prática do professor, enquanto a autonomia se refere aos alunos. Segundo essa teoria, para reformular as explicações de Macedo-Rouet, quanto mais a estrutura da aula é flexível e existe diálogo entre professores e aprendizes, menor é a distância da transação. Para Moore (1993), a videoconferência é a modalidade de ensino a distância que mais permitiria a possibilidade de reduzir a distância transacional.

1. 5 Interação professor-aluno, aluno-professor e aluno-aluno

Como vimos, de acordo com Moore (1993), as aulas por videoconferências permitem domar as distâncias. Ele também aponta para a possibilidade de desenvolver as interações entre alunos com essa tecnologia. Porém, essa possibilidade depende também do número de participantes e de como cada um desempenha seu papel.

Existem vários estudos analisando interações entre dois grupos de alunos que se encontram online para um intercâmbio cultural e linguístico. Trata-se de um modo privilegiado de usar a videoconferência pelos professores de língua para fomentar encontros interculturais. Como exemplo desse tipo de 
configuração, podemos mencionar o estudo de Xóchitl Espinosa Vasseur (2015), que traz as interações entre um grupo de estudantes franceses aprendendo o espanhol e um grupo de estudantes mexicanos aprendendo o francês. $\mathrm{O}$ autor mostra, por exemplo, de que forma os estudantes, incentivados a falar a língua estrangeira, se autorregulam e adotam estratégias para corrigir a sua pronúncia. Nesse tipo de estudos, as trocas entre estudantes são geralmente ricas e o professor está praticamente ausente no encontro. Exemplificando uma configuração oposta, podemos evocar os estudos sobre as interações entre um professor/tutor e um aluno, desenvolvidos por Guichon e Wigham (2015), que analisaram as interações entre um tutor de língua francesa nativo e um aprendiz irlandês de francês como língua estrangeira no âmbito dos estudos.

Porém, os dois tipos de configurações mencionados acima são bastante afastados da configuração que observamos no curso de extensão da UFF, em contexto de pandemia. De fato, em nosso caso, tratava-se de grupos de alunos junto com um instrutor de língua. Codreanu e Combe Celik (2012), ao estudarem a distribuição da fala em uma aula juntando dois alunos e um professor, mencionam a presença de "tensões interacionais" quando descrevem a participação desigual dos alunos e as tentativas do professor para equilibrar essa situação. Elas observam que o professor desempenha um papel de "gerenciador da interação" maior no contexto das aulas online, pois é ele quem distribui a fala e precisa antever mais as reações dos alunos do que em aulas presenciais. Isso requer dele uma preparação melhor para poder direcionar as perguntas, regular o discurso ou antecipar as respostas, de tal forma que as autoras falam em desenvolver um novo ethos.

O papel fundamental do professor para incentivar as interações em aulas mediadas por videoconferência é também descrito na dissertação de mestrado de Lorenzoni (2011). Apoiando-se nas teorias de Moore e Kearsley (2007), a pesquisa aponta para a grande importância do papel do professor nesse contexto de ensino online. Segundo Lorenzoni (2015, p.32), o professor dispõe de quatro técnicas para gerenciar as interações no ensino online: (a) humanização ("A criação de um ambiente que enfatize a importância do indivíduo e que gere uma sensação de relacionamento com o grupo"), (b) participação ("Assegurar que exista em um alto nível de interação e diálogo"), (c) estilo da mensagem ("Usar boas técnicas de comunicação ao apresentar as informações") e (d) feedback ("Obter informações dos participantes a respeito de seu progresso").

Para concluir, ao rever a literatura sobre o assunto e levando as nossas próprias reflexões decorrentes da nossa experiência, pareceu-nos que as aulas por videoconferência com grupos tendem a gerar mais interações entre alunos e professores do que entre os alunos entre si. Nesse tipo de configuração, 0 professor aparece como uma figura centralizadora das interações. Esse novo quadro levantou algumas perguntas em relação às possibilidades de desenvolver outros tipos de interações, em particular, das interações aluno-aluno. Nas próximas seções, apresentaremos mais detalhadamente 0 quadro educacional em que as nossas aulas foram dadas e, por último, dar alguns exemplos de atividades que tentamos desenvolver para incentivar as interações entre alunos.

\section{A experiência das aulas de língua online} em cursos de extensão de ensino de línguas estrangeiras na UFF

A UFF abriga dois projetos de extensão de ensino de língua: um projeto destinado para a comunidade interna de alunos, e outro para a comunidade interna e externa, e, portanto, aberto ao público. O projeto voltado para a comunidade em geral foi criado em 1997, é pago, porém sem fins lucrativos, com preços mais acessíveis que os cursos de idiomas tradicionais. O projeto procura valorizar a diversidade linguística e o multiculturalismo, e contempla, assim, o ensino de várias línguas: inglês, francês, espanhol, italiano, alemão, italiano, japonês, português para estrangeiros, russo, yorubá, guarani, grego, latim, LIBRAS, esperanto. O projeto tem um viés formativo para a área dos cursos de Licenciaturas em Línguas 
Estrangeiras da UFF, posto que os instrutores (bolsistas) que atuam como professores são alunos de Letras (graduação e pós-graduação), supervisionados por docentes do Departamento de Letras Estrangeiras Modernas. A progressão dos cursos de línguas estrangeiras é norteada pelo QECR.

Em relação ao segundo projeto de extensão da UFF, ele é mais recente, criado em 2012, e atende o público interno composto por de alunos da universidade. O projeto foi concebido no contexto das políticas afirmativas da universidade, seu principal objetivo é dar acesso gratuito à aprendizagem de uma língua estrangeira àqueles que não podem arcar com os custos de uma formação linguística. 0 conhecimento de línguas estrangeiras é uma das condições exigidas nos editais para a mobilidade acadêmica internacional. Nesse projeto de extensão, as línguas ensinadas são o alemão, o chinês, o espanhol, o francês, o inglês e o italiano. O projeto também tem caráter formativo, assim como no projeto voltado para a comunidade externa, e conta com alunos de graduação em línguas como instrutores (bolsistas), sob a supervisão de docentes do Departamento de Letras Estrangeiras Modernas. Os níveis ministrados vão do A1 ao B1.1.

\subsection{A transição para o ensino online}

No projeto de extensão aberto ao público em geral, a transição do ensino presencial para o ensino online ocorreu de forma muito rápida, em menos de uma semana, uma vez que o projeto seguiu as recomendações da universidade para 0 distanciamento social durante a pandemia. As medidas anunciadas pela universidade ocorreram no período de reinicio de aulas. Em um primeiro momento, as aulas foram marcadas por uma grande improvisação da parte dos professores, que tiveram uma certa liberdade para adaptar suas aulas presenciais. Os professores mantiveram a mesma carga horária, com os mesmos horários e continuaram seguindo o calendário oficial, inclusive os feriados. $O$ material pedagógico continuou sendo o mesmo, já que as provas seriam aplicadas em função do conteúdo.
Os grupos, que podiam ser constituídos de três alunos, mais comumente nos níveis mais adiantados, e de 23 a 30 alunos, em geral em níveis mais iniciais, permaneceram os mesmos.

Sendo assim, as aulas foram ministradas de forma síncrona por meio de plataformas de videoconferências, tais como Zoom, Meet ou Skype. Coube ao professor a escolha da plataforma. Observamos que o corpo de professores trabalhou de forma ainda mais colaborativa, discutindo os problemas e compartilhando soluções. Os professores também se empenharam em dividir os conhecimentos adquiridos em formações online voltadas para o ensino remoto.

O projeto de extensão para o público interno acompanhou o calendário oficial da universidade, e manteve apenas algumas atividades remotas, algumas síncronas e outras assíncronas, para manter os alunos em contato com a língua que estavam aprendendo. Durante o período de isolamento, os instrutores receberam formações para atuar no ensino remoto.

No segundo semestre de 2020, quando o retorno ao ensino presencial já estava descartado para o ano letivo, os dois projetos passaram a custear o acesso ao zoom para professores que haviam optado por essa plataforma.

\subsection{Um 115ontext excepcional: realidade e} questionamentos

Nesse contexto de isolamento social, como favorecer as interações? Como vimos acima, as interações online são caracterizadas pela multimodalidade: podemos falar por meio de um microfone, mandar sinais visuais pela webcam e escrever pelo chat, ou até pelo WhatsApp ao mesmo tempo. Guichon e Wigham (2015) ressaltam que, quando bem gerenciados, esses vários canais podem favorecer a aprendizagem. Porém, nos estudos acima citados, trata-se de contextos de aprendizagem com condições ideais. Muitas vezes, os estudos são feitos com sujeitos voluntários, que aderem ao sistema de 
ensino online, em laboratórios de língua, com um material tecnológico adequado.

Isto posto, parece-nos utópico querer utilizar como modelo os estudos feitos anteriormente, pois as condições em nada se comparam com aquelas que tivemos durante a quarentena, entre março e julho 2020. De fato, acreditamos que foi um quadro inédito, em que o "normal" ou o "recomendável" não existiu mais, pois as aulas online foram instauradas repentinamente, mediante um grande esforço e uma grande improvisação, tanto no plano tecnológico quanto pedagógico. Desse contexto inédito, surgiram muitas questões para os professores, em particular no que concerne às interações orais. Como fazer com que os alunos possam desenvolver a fala se não tiverem microfone ou webcam? Como incentivar as relações entre alunos, e não apenas de aluno a professor ou de professor a aluno? Como o professor pode distribuir a fala dos alunos? Como trabalhar competências comunicativas quando não se pode ver o seu interlocutor? Todas essas perguntas não têm uma resposta única ou definitiva. Um dos recursos que utilizamos foi de pedir gravações de Whatsapp para avaliar as competências orais. Porém, pode se dizer que um texto gravado é uma interação? Que tarefas pedir para avaliar as competências interacionais? Como se percebe, os questionamentos foram inúmeros e nos levaram a pensar e repensar o que se espera do aluno ao desenvolver tarefas orais na aula de língua estrangeira, bem como a dar mostras de inventividade para compensar as falhas da tecnologia. $\mathrm{Na}$ próxima seção, apresentaremos algumas atividades que desenvolvemos para incentivar a interação aluno-aluno em dois grupos de níveis distintos: uma turma de Iniciante I (A1) e uma turma de Avançado I (B1/B2).

\subsection{Interações entre alunos de nível iniciante}

Aprender um novo idioma é sempre uma tarefa que exige bastante dedicação, sendo também responsável por desenvolver a autonomia do aprendiz no processo de aprendizagem e interação em sala de aula. Mas quando a sala é virtual, algumas modificações são necessárias para mantermos o mesmo interesse e atenção dos alunos.

Para as turmas de nível iniciante, classificado como o nível $A 1$, procuramos criar atividades mais lúdicas. Os alunos iniciantes se sentem muito mais abertos ao diálogo com a turma quando passamos a enxergar o contexto como divertido, diminuindo sempre o fator inibidor que a câmera tem sobre nós para se confortar com um sorriso do outro lado da câmera.

Conforme vimos anteriormente, o modelo multimodal de Guichon e Cohen (2016) foi muito importante para o planejamento das sequências pedagógicas virtuais. De fato, a câmera representa um ponto crucial para o aprendizado de língua, sobretudo nos níveis iniciantes, já que ninguém se conhece. A linguagem não-verbal continua ocupando sua posição basilar na interação, mesmo na aula online.

$\mathrm{Na}$ turma de iniciantes, optamos pelo uso da plataforma Zoom. Para uma atividade sobre formulação de perguntas em francês, com o intuito de praticarmos as palavras interrogativas, a turma, composta por aproximadamente vinte alunos foi subdividida em quatro grupos de cinco alunos, dessa forma a atividade ficou mais organizada. Uma vez divididos, os alunos procuraram individualmente imagens na internet, sob a recomendação de que poderia ser uma pessoa, uma paisagem, algo a partir do qual the seriam postas perguntas sobre como, onde ou quando a imagem existia. A atividade ganhou resultado positivo imediato, com a participação expressiva de todos os alunos.

Outra atividade que despertou o interesse dos alunos iniciantes foi a formulação de um diálogo para pedir informações sobre como chegar a um destino. Novamente divididos em subgrupos de cinco alunos, os integrantes do diálogo preparavam a revisão de determinadas expressões linguísticas para a criação de um itinerário, atentos às possíveis intervenções que nós como instrutores fizéssemos no papel de turistas em seus diálogos, contribuindo assim com a progressão da dinâmica dessa atividade. Combinamos que o professor poderia intervir nesses pequenos grupos como se fosse transeunte que necessitasse de 
ajuda para chegar a um local específico da cidade. Com respostas simples e um direcionamento razoável da maior parte dos grupos, os alunos foram capazes de se situar na cidade e perguntar informações, relativamente útil quando estamos em um país de língua estrangeira e precisamos desesperadamente de ajuda, afinal saber se locomover é fundamental.

Através da técnica de humanização, elaborada por Moore e Kearsley (2007), os alunos sentiram sua participação de forma muito expressiva, entrando de fato na realidade da situação linguística e, assim, ao final da atividade demonstraram curiosidade sobre as diferentes expressões, comparando seu uso no francês com aquele em língua portuguesa, trazendo dúvidas sociolinguísticas provocadas através do contato com o idioma.

Segundo o glossário elaborado pelo Centro de Alfabetização, Leitura e Escrita (CEALE/UFMG), as professoras Raquel Salek Fiad e Maria da Graça Costa Val, abordam definem o conceito de produção de textos orais e escritos baseia-se em teorias linguísticas da enunciação, que consideram o texto como um resultado de um processo em que os sujeitos interagem através da linguagem. Através dessa perspectiva linguística, decidimos elaborar o exame de produção oral em forma de festival sociocultural.

Para elaboração da atividade, propusemos uma apresentação sobre um tema geral de interesse do aluno, a ser realizada individualmente ou em pequenos grupos. As apresentações seguiram a ordem estabelecida pelos horários marcados no documento virtual compartilhado em Google Drive. Alguns grupos compartilharam imagens de suas apresentações para ilustrar o conteúdo apresentado, outros criaram vídeos editados com caráter cômico, e outros optaram por expor oralmente sem ajuda de muitos recursos tecnológicos.

Finalmente, foi importante para compreender a dinâmica da atividade e a forma como os alunos se desenvolveram ao longo de toda a preparação dos documentos e conteúdos a serem apresentados no festival do semestre, visto que era uma atividade anunciada com quatro meses de antecedência. Dessa forma, pudemos desenvolver uma dinâmica que valorizasse a autonomia dos alunos, e sua capacidade argumentativa mesmo para alunos iniciantes no aprendizado do idioma.

2.4. Interações entre alunos de nível avançado

A turma de nível avançado era composta de treze alunos tendo o nível B1.2 ou B2.1, segundo o QECR. Era uma turma com alunos que participavam ativamente e eram bastante extrovertidos, o que fez com que a maior dificuldade não tivesse sido tanto incentivar a produção oral, mas gerenciar as interações e os debates. Todavia, com a transição para as aulas online, a dinâmica das aulas foi um pouco conturbada. Alguns alunos tiveram dificuldade para se conectar à plataforma Zoom, ou não tinham um material tecnológico adequado para essa modalidade. Apesar disso, todos quiseram participar e acompanharam as aulas até o fim do semestre. As primeiras interações foram às vezes complicadas, já que, com frequência, várias pessoas falavam ao mesmo tempo e não conseguimos identificar quem estava falando porque as câmeras estavam desligadas. Combinamos então que, sempre que possível, a melhor opção era manter a câmera ligada. De fato, a falta de imagem retira da comunicação muitos elementos pragmáticos que ajudam o professor a guiar o aluno: as expressões faciais, os movimentos da boca, os gestos da mão, etc., são elementos significativos para interpretar a mensagem de um interlocutor.

Uma turma bastante grande nos levou também a optar pelo desligamento do microfone enquanto os outros falassem, seja o professor, seja um aluno. Com efeito, as aulas em contexto de quarentena convivem com o ambiente doméstico de cada um, o que fez com que houvesse muitos ruídos "parasitas" nas aulas (obras, vizinhos, cachorros, etc.). O desligamento do microfone permite não "ocupar" o espaço da sala de aula virtual com esses ruídos, porém, essa opção apresenta também a desvantagem de tirar um pouco da espontaneidade das intervenções. Antes de cada fala, o aluno tem que reativar o microfone, para depois desligá-lo novamente. Esses obstáculos fizeram com que as intervenções fossem muito mais centralizadas em torno do professor do que em tempo normal. No 
início, as interações entre os alunos estavam bastante raras. A maioria das interações se dava pelo fato de os alunos fazerem perguntas para o professor, ou pelo professor fazer uma pergunta aberta a qual um aluno respondesse.

Foi principalmente através de atividades sob a forma de debate que conseguimos incentivar a fala espontânea entre alunos. Como parte da avaliação final dos alunos, foi pedido para eles prepararem uma apresentação sobre um filme francês, disponibilizado online no site do festival de cinema francês Varilux. Cada semana, um estudante escolhia um filme e preparava uma apresentação, que seria seguida de um debate. Todos podiam ver o filme antes da sessão para poder participar do debate de forma efetiva, porém não foi uma obrigação ver todos os filmes. O que era para ser apenas uma atividade avaliativa teve, em nossa opinião, um impacto bastante positivo nas produções orais dos estudantes. Muitas vezes, os estudantes terminaram as suas apresentações com uma pergunta que tinha como objetivo estimular o debate. Grande parte dos estudantes participou dos debates de forma ativa, propiciando trocas ricas e argumentadas em língua francesa. Adotamos voluntariamente uma atitude passiva durante esses debates: não interrompemos os estudantes, não corrigimos, não distribuímos a palavra. Também não interviemos durante as apresentações, com o intuito de os deixar na autonomia mais completa. Após o fim do debate, fazíamos uma revisão geral de itens gramaticais e lexicais, a partir das anotações sobre os erros feitas pelo professor durante a atividade.

A nosso ver, essa atividade foi bem-sucedida para incentivar as interações aluno-aluno por vários motivos. O primeiro deles foi que o tema das conversas, filmes franceses que apresentavam vários aspectos da sociedade francesa, era um tema "autêntico". De fato, os debates nasceram de perguntas que os alunos fizeram para outros alunos, e não a partir de um tema criado artificialmente pelo único propósito de fazer um debate em sala de aula. Dessa forma, a atividade assemelhou-se bastante a um cineclube. Comparado a outras atividades que fizemos a partir do livro, os debates cinematográficos incentivaram mais a fala porque eram temas autênticos e escolhidos pelos alunos. Em um contexto em que o contato humano acontece de forma tão artificial, por meio de artefatos tecnológicos, a necessidade de orientar as atividades de produção oral acerca de tema reais e não meramente didáticos se fez sentir mais fortemente. Como os debates não eram preparados, as trocas foram dadas de forma espontânea, o que instaurou um formato bastante flexível na aula. Como vimos anteriormente, a flexibilização da estrutura da aula é um fator que permite diminuir a distância transacional, segundo o modelo de Moore (2003).

Ter o professo apagado, invisível, como apontado por Leffa (2012), certamente ajudou também os alunos a sair da postura passiva e a participar mais da atividade. Primeiro, porque eles podiam experimentar a situação de falar sozinho no microfone sem ver os outros, já que durante a apresentação, falavam sozinhos quase 10 minutos, frente a 14 microfones e câmeras desligados. Essa configuração é particularmente desconfortável, o que, acreditamos, incentivou os alunos a procurar a opinião dos outros após a apresentação e a dinamizar o debate. De uma certa forma, eles ocuparam o lugar do professor por um breve momento e isso ajudou a inverter um pouco a organização das interações.

Por fim, o fato de saber que não iriam ser interrompidos talvez facilitou também a participação dos alunos. Em alguns aspectos, comunicar em uma língua estrangeira na aula online é bastante desconfortável, pois se trata de um modo de comunicação totalmente novo para a maioria dos estudantes. Uma atitude mais flexível em relação ao erro pode ajudar também. Quando um aluno demonstrava uma insegurança em relação a uma palavra durante a apresentação ou debate, o professor podia dar um retorno discreto, acenando a cabeça ou o polegar, para confortá-lo. O apagamento do professor durante essa atividade foi benéfico para o desenvolvimento da autonomia do aluno, elemento particularmente importante para reduzir a distância transacional de acordo com Moore (1993).

\section{Considerações Finais}


Ao longo desse artigo, vimos que a chegada da pandemia Covid-19 no Brasil desencadeou vários desafios para o ensino de línguas estrangeiras. $\mathrm{Na}$ UFF, essa situação levou os dois projetos de extensão a operar uma transição rápida para aulas remotas, e, em ambos, apesar das dificuldades, a maioria dos alunos desejou continuar as aulas e seguiu participando normalmente. Assim, pretendemos trazer algumas considerações a respeito dessa reflexão.

O formato apresenta determinadas vantagens, uma vez que permitiu a continuação das aulas na universidade, colocando de lado as antigas dificuldades estruturais de locomoção típicas de uma grande cidade e resumindo-as ao acesso à internet. Isso, de fato, permitiu utilizar as habituais horas perdidas nos trajetos e engarrafamentos pela área urbana no planejamento individual dos alunos a partir de suas próprias residências. Entretanto, o novo formato também é fonte de dificuldades no que se refere ao acesso às condições materiais requeridas para acompanhar esse tipo de aulas.

No âmbito institucional, destacamos a ação social realizada pela Divisão de Serviço Social da UFF, que vem concedendo bolsas de apoio emergencial aos estudantes que necessitam de um auxílio financeiro para permanecer na Universidade. As bolsas oferecidas visam atender os estudantes regularmente matriculados em disciplinas de cursos de graduação e pós-graduação, podendo ser concedidas por até três meses ao estudante. A UFF também lançou o Programa Integrado de Acesso Digital e Apoio às Atividades Remotas. Essa iniciativa tem o objetivo de promover ações de qualidade no ensino por meio da inclusão e acesso digital de estudantes em situação de vulnerabilidade. Segundo dados obtidos no site oficial da Universidade, todos os estudantes que participaram do programa foram contemplados com alguma modalidade de assistência, totalizando 4.534 solicitações atendidas. Os programas investem cerca de $R \$ 680$ mil reais mensais do recurso de assistências estudantil, além dos contratos de equipamentos que foram emprestados aos estudantes.
No plano didático, o gerenciamento das interações online foi um grande desafio. Conforme observamos, a modalidade online tende a favorecer as interações professor-aluno, em detrimento das interações aluno-aluno. Enquanto professores de língua francesa, isso nos levou a pensar em atividades pedagógicas que permitissem reequilibrar a distribuição das interações. Tanto em aulas de nível iniciante quanto de nível avançado, observamos que as atividades que mais incentivam os alunos a interagir entre si são aquelas em que o professor se faz menos presente. A insegurança suscitada pelo formato online pode levar professores a buscar controlar a aula mais do que o habitual, seja no planejamento da aula ao pensar em inúmeras falhas possíveis que prejudicariam a dinâmica pedagógica, seja no gerenciamento das interações entre as partes do processo interativo. Nós observamos durante algumas aulas que a insegurança está presente até mesmo no silêncio que se instala após uma determinada orientação que não é compreendida ou mal formulada na tentativa de adaptação de uma atividade ao ambiente virtual ou, ainda, diante de uma falha tecnológica de ambas as partes, o que é comum e perfeitamente compreensível nessa forma de interação. Todavia, nos parece que é justamente quando há menos planejamento e menos gerenciamento das interações que os alunos começam a interagir entre si. Ou seja, pode ser profícuo para o aluno, mas também para o professor essa "invisibilidade" (LEFFA, 2012) em determinados momentos.

Com efeito, após a análise do processo de interatividade em ensino de língua estrangeira e de nossa experiência empírica em aulas na modalidade remota, identificamos que existe uma ligação entre a proposta multimodal elaborada por Guichon e Cohen (2016) e a proposta da invisibilidade do professor com seu processo de autonomia, sobretudo em Ambientes Virtuais. Segundo Leffa (2012), no início o professor era o centro da sala, depois foi para a margem, mais tarde ficou distante e sua previsão é de que futuramente desaparecerá na invisibilidade, sendo esse conceito explicado pelo autor como uma relação 
benéfica na qual quanto mais longe dos olhos do aluno ficar o professor, maior poderá ser sua ação sobre ele, desde que seja capaz de se preparar para ocupar os espaços que se abrem entre ele e o aluno, abrangendo áreas cada vez maiores.

Compreender o aprendiz como participante do processo pedagógico, a promoção da interatividade, considerada como uma forma de diálogo fundamental, a valorização do conhecimento gerado pela autonomia do aluno se aproxima da educação à distância interativa e colaborativa. A interatividade possui uma importância muito grande no ensino e na aprendizagem remota, afinal é essa ferramenta que possibilita o contato entre os diversos atores inseridos no contexto virtual.

A independência proposta por Leffa (2012) para o ensino e aprendizagem leva consigo valores imprescindíveis como o respeito ao saber, ao conhecimento empírico e ao processo histórico e cultural do indivíduo, a constante pesquisa de práticas pedagógicas, uma vez que ensinar é possibilitar a consolidação do saber, ainda que em ambientes virtuais que valorizem essa interatividade. Para esta prerrogativa, para que 0 ensino remoto seja considerado uma modalidade interativa e ainda colaborativa, é necessário fomentar a autonomia do aluno em sala virtual, preferencialmente em um contexto de inclusão digital e social mais democrático.

\section{REFERÊNCIAS}

ABED. Censo digital EAD 2018. Disponível em: $<$ http://abed.org.br/arquivos/CENSO_DIGITAL_ EAD_2018_PORTUGUES.pdf> Acesso em $06 / 08 / 2020$.

AGÊNCIA BRASIL. Um em cada 4 brasileiros não têm acesso à internet, mostra pesquisa. Disponível em: <https://agenciabrasil.ebc.com.br/economia/ noticia/2020-04/um-em-cada-quatro-brasileiros-naotem-acesso-internet> Acesso em 06/08/2020.

BAKHTINE, Mikhail. Marxismo e filosofia da linguagem, 12. ed. São Paulo: Hucitec, 2006. 201 p.

BELLONI, Maria Luiza. Ensaio sobre a Educação a Distância no Brasil. Educação \& Sociedade, São Paulo, ano XXIII, no 78, p. 117-142,
Abril/2002.

Disponível em <https://www.scielo.br/pdf/es/v23n78/a08v2378.pdf> BRASIL. Lei no 9.394. Estabelece as diretrizes e bases da educação nacional. Brasília: DOU, 1996.

BRASIL. Parâmetros Curriculares Nacionais; apresentação dos Temas Transversais. Secretaria de Educação Fundamental, Brasília, MEC/SEF, 1997.

CONSELHO DA EUROPA. Quadro europeu comum de referência para as língua: aprendizagem, ensino, avaliação. Serzedo: Edições Asa, 2001.

CODREANU, Tatiana; COMBE CELIK, Christelle. La médiation de l'interaction pédagogique sur une plateforme de visioconférence poste à poste. Alsic, n. 3, v. 15, 2012.

Disponível

em: http://journals.openedition.org/alsic/2572. Acesso em: 06/08/2020.

CICUREL, Francine. De l'analyse des interactions en classe de langue à l'agir professoral : une recherche entre linguistique interactionnelle, didactique et théories de l'action . Pratiques, n. 149150, p. 41-55, 2011.

ESPINOSSA VASSEUR, Xóchitl. Communiquer autrement à travers la visioconférence: outil miracle ou frein pour apprendre une langue ? Synergies Mexique, n. 5, p. 101-113, 2015.

FRADE, Isabel Cristina Alves da Silva; COSTA, Maria da Graça Val; BREGUNCI, Maria das Graças de Castro (orgs). Glossário CEALE: termos de alfabetização, leitura e escrita para educadores, Belo Horizonte: UFMG/Faculdade de Educação, 2014. Disponível em: $<$ http://www.ceale.fae.ufmg.br/app/webroot/glossarioc eale/> Acesso em 06/08/2020.

GUICHON, Nicolas; COHEN, Cathy. Multimodality and CALL. In: FARR, Fiona; MURRAY, Liam (orgs.). The Routledge Handbook of Language Learning and Technology. London: Routledge. 2016. p. 509-521.

GUICHON, Nicolas; WIGHAM, Ciara. A semiotic perspective on webconferencing-supported language teaching. ReCALL, n. 28, v.1, p. 62-82, 2015.

HARGREAVES, Luiz Henrique Horta. Ensino de inglês a distância: análise de diferentes cursos. 1. ed. Brasília: Clube dos autores, 2011. 74 p.

KEREMIDCHIEVA, Greta; YANKOV, Plamen. Challenges and advantages of distance learning systems, 2001. Information \& Security: An International Journal. 6. 115-121. Disponível em:

$<$ https://procon.bg/system/files/06.09_Keremidc hieva_Yankov.pdf> Acesso em 08/08/2020. 
KERN, Rick; WARE, Paige. WARSCHAUER, Mark. Network-Based Language Teaching. 1. ed. Cambridge: Cambridge University Press, 2000. 252 p.

LEFFA, Vilson. Ensino de línguas: passado, presente e futuro. Universidade Católica de Pelotas/CNPq. Rev. Est. Ling., Belo Horizonte, v. 20, n. 2, p. 389-411, jul./dez. 2012.

LORENZONI, Carla Raqueli Navas. Teleencuentros: análise da atividade didática mediada por videoconferência no ensino de espanhol. 2011. 107 f. Dissertação (Mestrado em Linguística e Língua Portuguesa) Universidade Estadual Paulista, Faculdade de Ciências e Letras, Campus de Araraquara, 2011.

MACEDO-ROUET, Mônica. La visioconférence dans l'enseignement. Ses usages et effets sur la distance de transaction. Distances et savoirs, v. 7, p. 65-91, 2009.

MOORE, Michael. Theory of transactional distance. In: KEEGAN, Desmond (org.), Theoretical Principles of Distance Education. London: Routledge. 1993. p. 20-35.

MOORE, Michael, KEARSLEY, Greg. Educação a distância: uma visão integrada. São Paulo: Thompson Learning. 2007.

NASCIMENTO, Iracema Santos do; SANTOS, Patrícia Cerqueira dos. A normalidade da desigualdade social e da exclusão educacional no Brasil. Caderno de Administração, Maringá, n. 28, p. 122-130, jun. 2020.

PAIVA, Vera Lúcia Menezes de Oliveira e. Tecnologias digitais no ensino de línguas: passado, presente e futuro. Revista da Abralin, v. 18, n. 1, p. 0226, 2019.

TUMOLO, Celso Henrique Soufen. Ensino a distância: horizontes para 0 ensino de línguas estrangeiras. Fragmentos, Florianópolis, n. 30. p. 2534, jan.-jun. 2006.

UFF, Programa Integrado de Acesso Digital e Apoio às Atividades Remotas. Disponível em:

http://www.uff.br/?q=noticias/16-10-2020/uffcontempla-100-dos-pedidos-de-auxilio-inclusaodigital-e-abrira-novos-editais, acesso em nov. 2020

WARSCHAUER, Mark. Computer Assisted Language Learning: an Introduction. In: FOTOS,
Sandra. ed. Multimedia Language teaching, Tokyo: Logos International, p. 3-20, 1996.

RIOULT, Nina; MARRON, Adilson; PEREIRA, Telma Aulas virtuais: uma discussão sobre a interação no aprendizado de língua estrangeira em tempos de pandemia. Signo, Santa Cruz do Sul, v. 46, n. 85, p. 108121, jan. 2021. ISSN 1982-2014. Disponível em: <https://online.unisc.br/seer/index.php/signo/article/view/ 15617>. doi:https://doi.org/10.17058/signo.v46i85.15617. 